Proceedings of XIX International Scientific Conference "New Technologies and Achievements in Metallurgy, Material Engineering, Production Engineering and Physics", Częstochowa, Poland, June 7-8, 2018

\title{
The Influence of Reinforcement Fibers on Mechanical and Electrical Properties of the Electrical Engineering Composites
}

\author{
A. Jakubas*, M. Chyra and A. Gnatowski \\ Częstochowa University of Technology, J.H. Dąbrowskiego 69, 42-201 Częstochowa, Poland
}

\begin{abstract}
The article presents an analysis of the influence of the qualitative and quantitative composition of composites on their electrical conductivity and mechanical properties. Composites of this type are the subject of research on the possibility of shielding the electromagnetic field. For this purpose, samples of composites based on recycled metal materials were prepared. Metal flakes were mixed in fixed amounts by weight with PVC powder. Various types of reinforcing fibers were added to the mix. Short fibers were obtained by grinding textile and cellulose materials. The samples thus prepared were formed under pressure. The following tests were made on such samples: hardness, elongation and deflection forces, impact tests, electrical conductivity. The analysis of mechanical data and the results of resistance measurements enables the development of a model describing the relationship between these parameters and the quantitative composition and kind of reinforcement of the presented composites.
\end{abstract}

DOI: 10.12693/APhysPolA.135.193

PACS/topics: mechanical and electrical properties, composites, waste materials, fibers, polymers

\section{Introduction}

Polymer matrix composites (PMC) are often used in various industries. One of their possible applications are durable panels shielding of the electromagnetic field in a wide range of frequencies [1]. Yet another one are magnetic cores for the electrical industry [2]. This fact is due to the possibility of improving the mechanical properties of the base material and lowering the price of the final product [3-5]. Increased durability and stiffness of the composite is achieved by the addition of short fibers of other materials (e.g. polymer, natural, metal). The properties of composite products depend not only on the type of filler, but also on structural factors of the matrix and reinforcement (molecular weight, physical structure of the chain, crystallinity, chemical structure of macromolecules, molecular orientation). The operating conditions are: temperature, load time, pressure, deformation, electrical properties, etc. [6-8]. Research related to the impact of reinforcing fibers can be found, inter alia, in [9]. The authors investigated the influence of the fiber-matrix adhesion degree on the mechanical properties of the composite. Joshi et al. [10] compared the possibilities of using various natural reinforcing fibers instead of glass fibers. $\mathrm{Li}$ et al. [11] described methods of modifying reinforcing fibers that increase adhesion to the matrix.

\section{Material and methods}

Samples for testing were made of fine aluminum chips and suspension polyvinyl chloride (PVC). Various types of short fibers were added to the mixture prepared in

*corresponding author; e-mail: adam.jakubas@gmail.com this way, sample specifications are given in Table I. Samples with dimensions of $80 \times 80 \times 4.5 \mathrm{~mm}^{3}$ were formed at $55 \mathrm{MPa}$ pressure at $\mathrm{PVC}$ plasticity temperature $-165^{\circ} \mathrm{C}$.

Specification of samples.

TABLE I

\begin{tabular}{l|c|c|c|c|c}
\hline \hline & P0 & P1 & P2 & P3 & P4 \\
\hline$\% \mathrm{Al}$ & 70 & 70 & 70 & 70 & 70 \\
\% PVC & 30 & 30 & 30 & 30 & 30 \\
+ fibers & - & PA & cotton & cardboard & PE \\
weight $[\mathrm{g}]$ & 55 & 53.5 & 56.5 & 56.3 & 56.2 \\
density $\left[\mathrm{g} / \mathrm{cm}^{3}\right]$ & 2.0 & 2.1 & 2.1 & 2.1 & 2.1
\end{tabular}

A number of tests were carried out on prepared samples:

- Hardness tests were carried out using the method of ball indenter.

- The impact was tested by the Charpy method on a $5 \mathrm{~J}$ pendulum hammer. Before the tests an A-type notch was cut in the samples.

- The analysis of dynamic thermal properties was performed on the NETZSCH DMA 242 device. For the sample placed in the holder, through the mandrel, sinusoidal forces of variable force were introduced at a frequency of $1 \mathrm{~Hz}$ and $10 \mathrm{~Hz}$ with a constant amplitude. At the same time samples were heated at a rate of $3{ }^{\circ} \mathrm{C} / \mathrm{min}$ from $20^{\circ} \mathrm{C}$ to $220^{\circ} \mathrm{C}$. On the basis of force and strain (taking into account the dimensions of the sample), the conservation modulus $E^{\prime}$ and loss modulus $E^{\prime \prime}$ and the mechanical loss factor $\tan \delta$ were calculated.

- The static bending test was carried out using an Hektewald\&Peschke Inspekt Desk 20 testing machine. 
- Resistance measurement was carried out with the low resistance meter Sonel MMR-620 and a set of electrodes.

\section{Measurements}

Material properties were determined using the abovementioned devices. The results of the hardness measurement are shown in Fig. 1.

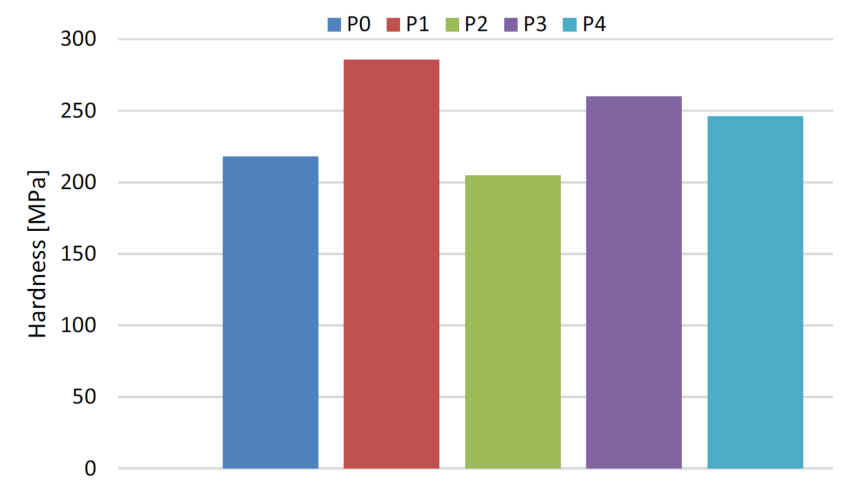

Fig. 1. Hardness determined method of ball indenter.

Hardness above $200 \mathrm{MPa}$ was recorded for all tested samples. The highest value i.e. $286 \mathrm{MPa}$, was obtained
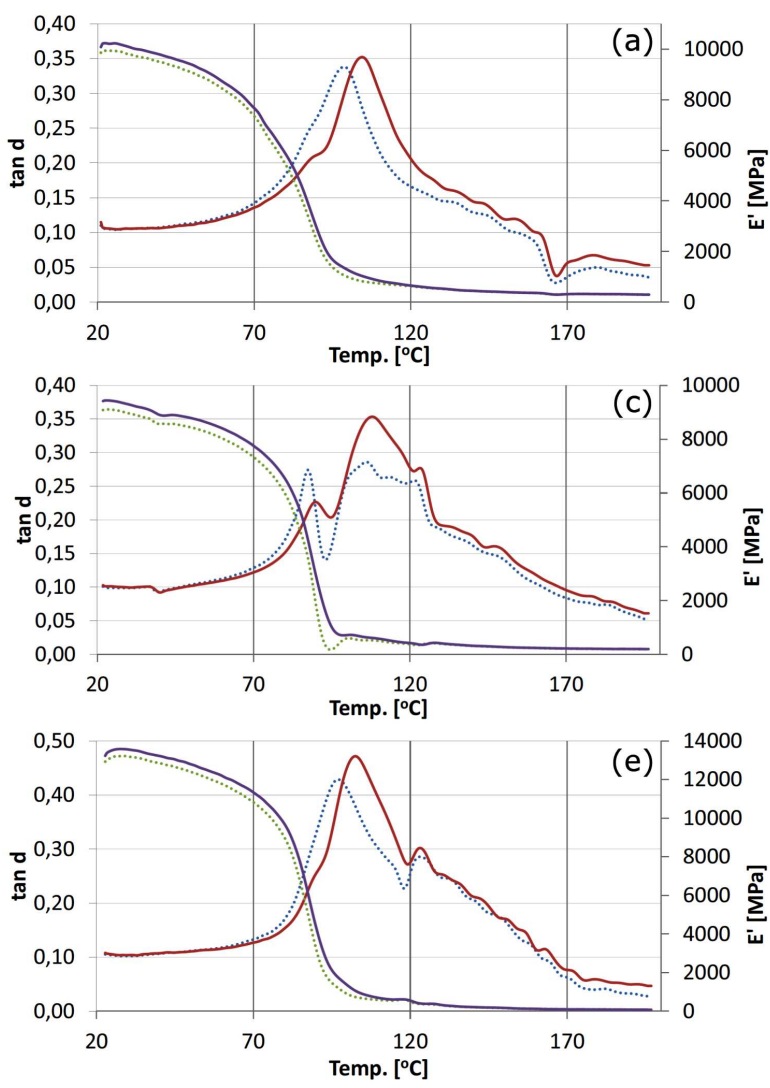

by sample P1 with reinforcement made of cotton fibers, whereas the lowest value was obtained for P2 composite (cardboard fibers) - $205 \mathrm{MPa}$.

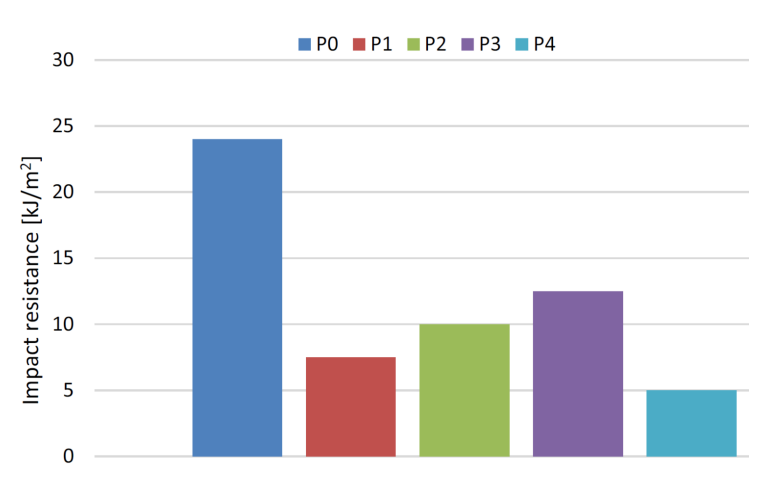

Fig. 2. Results of toughness investigations.

Figure 2 shows the results of impact resistance tests. The highest impact value, equal to $24 \mathrm{~kJ} / \mathrm{m}^{2}$, was recorded for P0 samples. Significantly smaller indications were obtained for the remaining composites. For the sample $\mathrm{P} 5$ the smallest value equal to $5 \mathrm{~kJ} / \mathrm{m}^{2}$ was measured.

The values of the conservative modulus and tangent angle of losses obtained during the DMTA study are presented in Fig. 3.
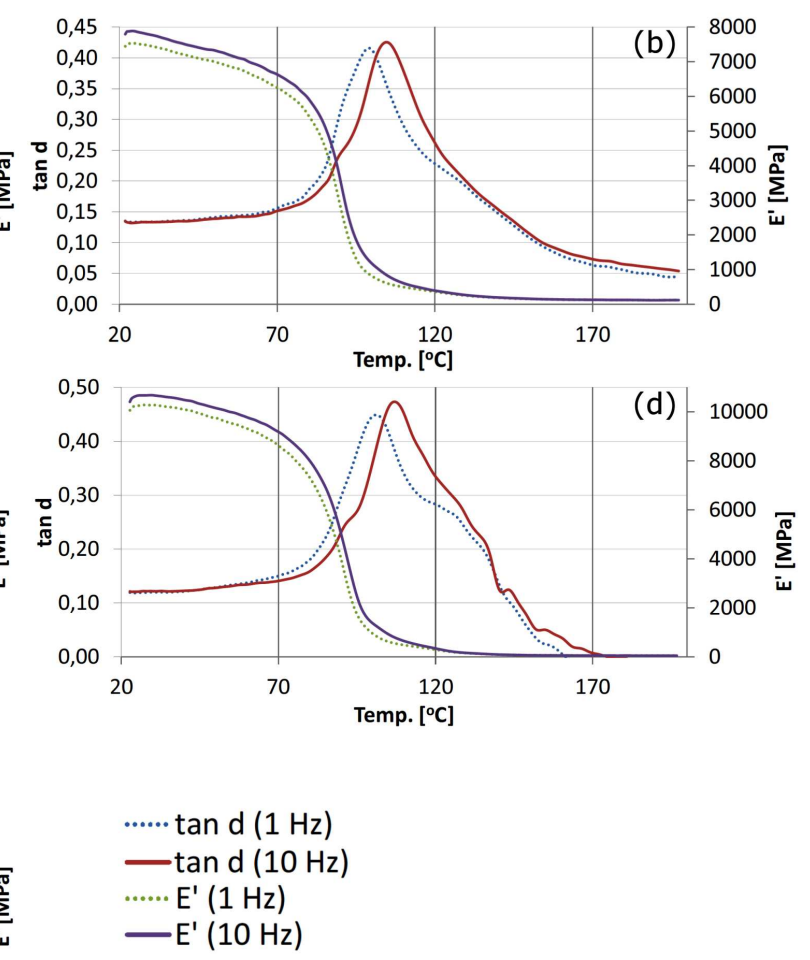

Fig. 3. The values of the conservation modulus $E^{\prime}$ and $\tan \delta$ as a function of temperature at different frequencies for: (a) P0, (b) P1, (c) P2, (d) P3, (e) P4. 
The tests showed that the samples are characterized by a significant difference in the level of highly elastic deformation. For the sample P1, the module values are much lower. In this case, a much smaller effect of temperature was recorded on changes in the conservative module. The highest values of the conservative module were recorded for P4 samples. Differences in values are up to $30 \%$ in relation to the P0 sample. The difference between materials is blurred in the final operating range, at a temperature of $80-120^{\circ} \mathrm{C}$, the values of the conservation module $E^{\prime}$ are very similar.

Analysis of the recorded values of the mechanical loss factor indicates differences for the tested materials. The change trend for $\tan \delta$ in the range frequency 1 and $10 \mathrm{~Hz}$ indicates comparable stiffness and vibration damping in the tested materials. However, some differences appear in the intensity of the wave. For samples P3 and P4 the highest values of the maximum tangent of the loss angle were recorded.

The results of bending strength tests are shown in Fig. 4.

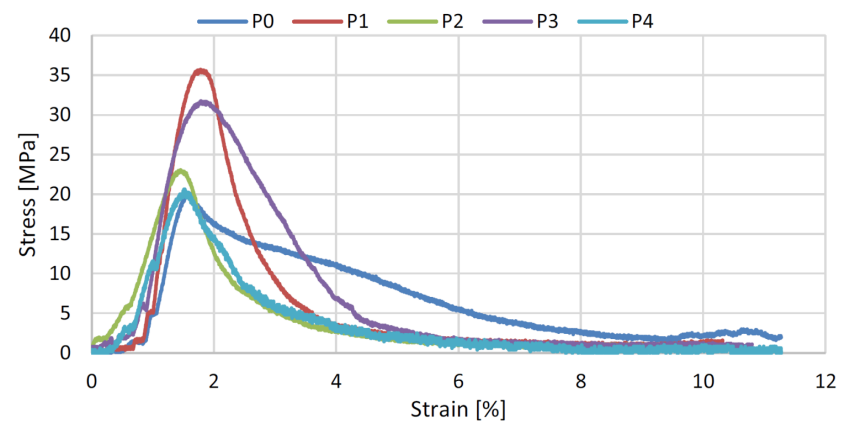

Fig. 4. Results of resistance to bending investigations.

TABLE II

List of measurement data.

\begin{tabular}{l|c|c|c|c|c}
\hline \hline & P0 & P1 & P2 & $\underline{\underline{\mathrm{P} 3}}$ & P4 \\
\hline hardness $[\mathrm{MPa}]$ & 218 & $\underline{\underline{286}}$ & 205 & $\underline{\underline{260}}$ & 246 \\
toughness $\left[\mathrm{kJ} / \mathrm{m}^{2}\right]$ & $\underline{\underline{24}}$ & 7.5 & 10 & $\underline{\underline{12.5}}$ & 5 \\
bending $[\mathrm{MPa}]$ & 20 & $\underline{\underline{35}}$ & 23 & $\underline{\underline{31}}$ & 20 \\
$\tan \delta 10 \mathrm{~Hz} \max$ & 0.35 & 0.43 & 0.35 & $\underline{\underline{0.47}}$ & $\underline{\underline{\underline{0.47}}}$ \\
$E^{\prime} 10 \mathrm{~Hz} \max$ & 10237 & 7888 & 9440 & $\underline{\underline{10685}}$ & $\underline{\underline{\underline{13581}}}$ \\
resistance $R_{S}[\mathrm{~m} \Omega / \mathrm{mm}]$ & 0.08 & $\underline{\underline{0.29}}$ & 0.11 & $\underline{\underline{0.12}}$ & 0.1 \\
resistance $R_{V}[\mathrm{~m} \Omega / \mathrm{mm}]$ & 42.4 & $\underline{6.4}$ & $\underline{\underline{71.3}}$ & $\underline{\underline{75.3}}$ & 47
\end{tabular}

The highest value of bending strength of $35 \mathrm{MPa}$ was measured for sample P1. In turn, the lowest bending strength $-20 \mathrm{MPa}$ - was recorded for the composite $\mathrm{P} 4$.
The addition of reinforcing fibers to the composite caused an increase in the value of electrical resistance. The highest value of the surface resistance $R_{S}$ has the sample P1 $-0.29 \mathrm{~m} \Omega / \mathrm{mm}$. At the same time the P3 sample obtained the highest value of volume resistance - $75.3 \mathrm{~m} \Omega / \mathrm{mm}$. Table II shows the measured values for all samples and tests.

\section{Conclusions}

Adding the reinforcement to the Al-PVC composite allows one to tailor up mechanical properties of the developed materials. The tested composites have better thermomechanical properties than the reference material P0. In Table II, the maximum values obtained in the measurements were double underlined and the second values in turn were underlined. Analysis of these results indicates that the best overall properties are characterized by a sample with reinforcement from cardboard fibers.

The electrical resistance has also changed. There has been a general increase in its value. In addition, the structure of the composite caused that the volume resistance value is much greater than the surface resistance.

The use of recycled materials such as aluminium or steel chips, polymer matrix and reinforcing fibers (also obtained from recycling) allows to develop construction materials for use in the energy and electronics industry with the desired mechanical and electrical properties.

\section{References}

[1] D. Bambynek, A. Jakubas, P. Jabłoński, Przegląd Elektrotechniczny 1, (2017) (in Polish).

[2] A. Jakubas, P. Gębara, S. Seme, A. Gnatowski, K. Chwastek, Acta Phys. Pol. A 131, 1289 (2017).

[3] A. Gnatowski, A. Ziewiec, R. Gnatowska, AIP Conf. Proc. 1648, 850127 (2015).

[4] I. Legocka, E. Wierzbicka, M.J. Talal, Al-Zahari, O. Osawaru, Polimery 2013, 24 (2013) (in Polish).

[5] J. German, Podstawy Mechaniki kompozytów wtóknistych, Politechnika Krakowska, Katedra wytrzymałości Materiałów, WydziałInżynierii Lądowej, Kraków 2001 (in Polish).

[6] A.L. Holbrook, Int. J. Powder Metall. 22, 39 (1986).

[7] Q. Xue, Europ. Polym. J. 40, 323 (2004).

[8] Y.C. Zhang, Y.F. Huang, K. Dai, H. Pang, C. Chen, Z.M. Li, Polymer Plastic Technol. Eng. 5, 1511 (2000).

[9] P. Herrera-Franco, A. Valadez-Gonzalez, Composit. Part B Eng. 36, 597 (2005).

[10] S.V. Joshi, L.T. Drzal, A.K. Mohanty, S. Arora, Composit. Part A Appl. Sci. Manufact. 35, 371 (2004).

[11] X. Li, L.G. Tabil, S. Panigrahi,J. Polym. Environm. 15, 25 (2007). 